\title{
Electrochemical Preparation of Sub-micrometer Sn-Sb Alloy powder in ChCl-EG deep eutectic solvent
}

\author{
Zhaolei Su ${ }^{1,2}$, Cunying $\mathrm{Xu}^{1,2, *}$, Yixin Hua ${ }^{1,2}$, Jian $\mathrm{Li}^{1,2}$, Juanjian $\mathrm{Ru}^{1,2}$, Mengmeng Wang ${ }^{1,2}$, Li Xiong $^{1,2}$, \\ Yadong Zhang ${ }^{1,2}$ \\ ${ }^{1}$ Faculty of Metallurgical and Energy Engineering, Kunming University of Science and Technology, \\ Kunming 650093, P. R. China \\ ${ }^{2}$ State Key Laboratory of Complex Nonferrous Metal Resources Cleaning \\ Utilization, Kunming, 650093, P. R. China \\ *E-mail: xucunying@foxmail.com, xucunying@kmust.edu.cn
}

doi: $10.20964 / 110446$

Received: 7 February 2016 / Accepted: 11 March 2016 / Published: 1 April 2016

The sub-micrometer $\mathrm{Sn}-\mathrm{Sb}$ alloy powders were electrochemically prepared on a titanium substrate in choline chloride-ethylene glycol (ChCl-EG, 1:2 molar ratio) deep eutectic solvent containing $0.2 \mathrm{M}$ $\mathrm{SbCl}_{3}$ and $0.2 \mathrm{M} \mathrm{SnCl}_{2}$. The electrochemical behaviors of $\mathrm{Sb}$ (III) and $\mathrm{Sn}$ (II) were investigated using cyclic voltammetry techniques. It revealed that the reduction of $\mathrm{Sb}$ (III) and $\mathrm{Sn}(\mathrm{II})$, as well as coreduction of them in ChCl-EG involved the irreversible process controlled by diffusion. The diffusion coefficients of $\mathrm{Sb}$ (III) and $\mathrm{Sn}(\mathrm{II})$ species were in the range of $10^{-7}$ and $10^{-6} \mathrm{~cm}^{2} \mathrm{~s}^{-1}$, respectively. Potentiostatically deposited $\mathrm{Sn}-\mathrm{Sb}$ alloys were characterized by inductively coupled plasma atomic emission spectrometry (ICP-AES), scanning electron microscopic (SEM) and X-ray diffraction (XRD). The deposition potential played an important role in controlling the composition, but had little effect on surface morphology. Depending on the deposition potential, sub-micrometer Sn-Sn alloy powders containing about 2.7-67.4 at.\% Sn were obtained.

Keywords: Deep eutectic solvent; Sn-Sb alloy; Dlectrodeposition; Sub-micrometer.

\section{FULL TEXT}

(C) 2016 The Authors. Published by ESG (www.electrochemsci.org). This article is an open access article distributed under the terms and conditions of the Creative Commons Attribution license (http://creativecommons.org/licenses/by/4.0/). 